\title{
HERITAGE WALKS AS A TOOL FOR PROMOTING SUSTAINABLE HISTORICAL TOURISM
}

\author{
Joby Thomas*
}

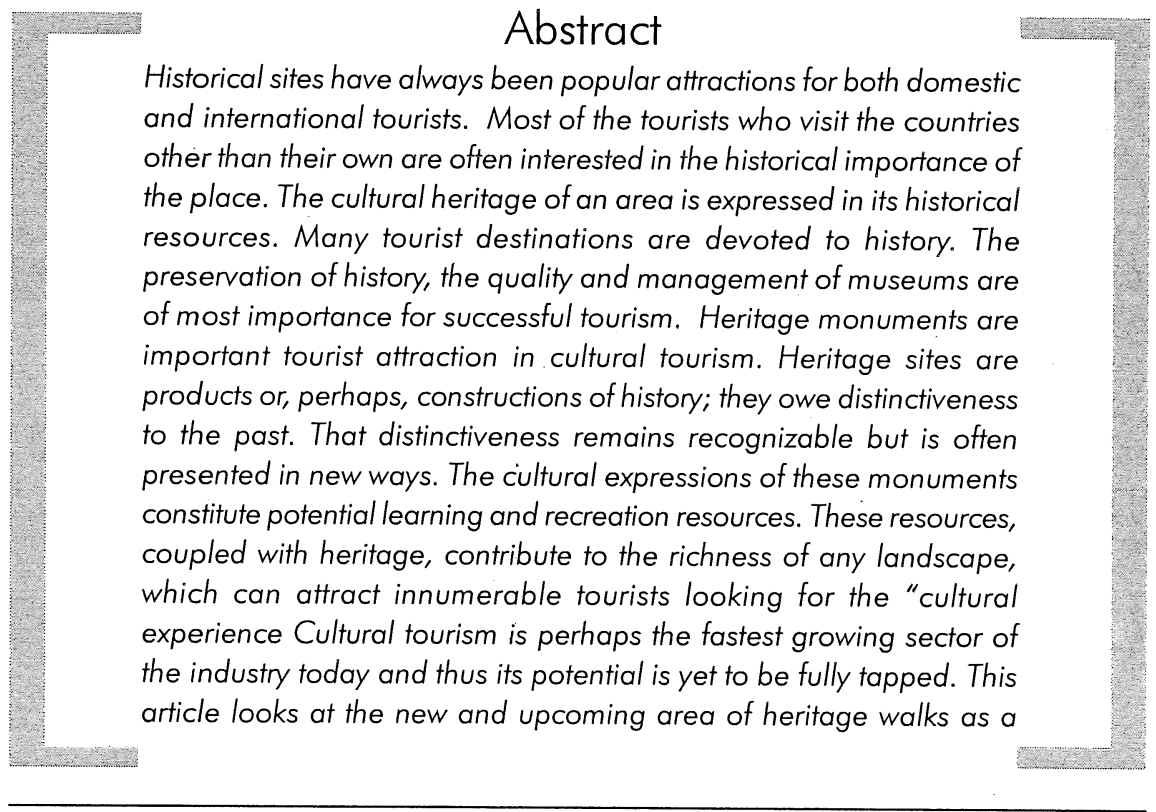

* Department of Tourism Studies, Christ University, Bangalore. 


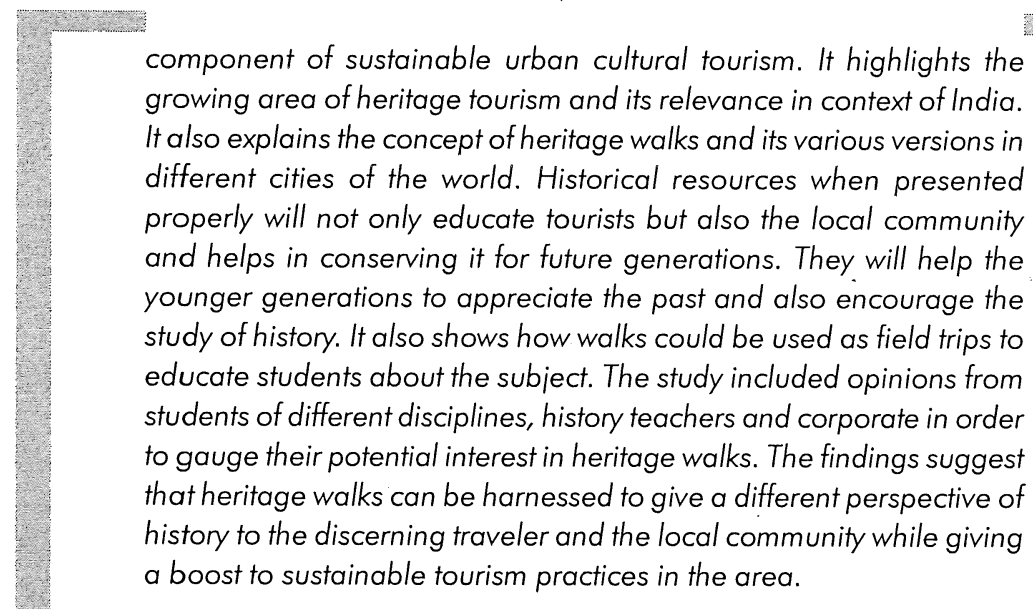

\section{Introduction}

Heritage tourism has become the new buzzword in recent times. It has experienced a great boom in the country and also internationally. Cultural tourism is one aspect of this vast field. Heritage tourism is concentrated on discovering and experiencing the past in the present. It includes visits to natural, cultural or built heritage sites. The main reason that people engage in cultural and more specifically, heritage tourism, is because of their search for new and unique visitor experiences. As the world grows smaller, people are becoming increasingly aware of different cultures and their history. Thus, they are willing to travel to different places of the world to experience them.

Different categories of heritage attractions present a variety of choices for those interested in travel. With regard to travel associated with experiencing a culture and its traditions, it not only results in a more enriched traveler, but also serves to remind the local community that their traditions and practices are of importance and interest to others. They realize that it is therefore important to conserve their unique practices for future generations as they can draw even more tourists, both domestic and international. Historical attractions have always been popular as tourist attractions. However, they were never packaged separately or looked at as the sole reason for travel. With interest in built heritage increasing day by day, this is changing slowly but surely. The urban cultural tourist is becoming a lucrative segment. People are now aware about the history of different countries and cultures. They are willing to travel long distances to walk in the footsteps of great kings and warriors, hear legendary tales and admire the awe-inspiring architecture. 
Heritage tourism is important for socio-economic reasons too. It enriches the lives of travelers and leads them to appreciate the world and its diverse cultures. At the same time, it instills in the host community a renewed pride in their history and traditions. Both communities realize the need for protecting and conserving the culture and its manifestations. Thus, heritage tourism is to be encouraged as an important component of sustainable tourism. Tourism of any kind is always beneficial to the region where it takes place. It provides employment to the local people, raises their standards of living, etc.

\section{Scenario in India}

To Western travellers, India has always been a symbol of mystery, representing the unknown. Explorers, pilgrims and travellers have been coming to the country for centuries in order to discover its culture and traditions. India has a long and tumultuous past that has left behind many great monuments. In addition, it is a very vast and diverse country. Each state has its own language, culture, festivals and traditions. Thus, India is the perfect destination for cultural tourists.

The Government of India has, in recent years, realized the great potential that heritage tourism has in the country. It has encouraged the various heritage projects including heritage railways and heritage hotels, to name a few and promotes sustainable heritage tourism. The sector received a huge boost in 2008, when the National Budget announced tax holidays for the next five years for setting up two, three and four star hotels at India's World Heritage Sites.

Heritage tourism is a vast field. For India, the possibilities are endless. Proper infrastructure is the major concern at this point of time. However, since the Government is encouraging tourism in general and heritage tourism in particular, there is certainly a bright future for this sector in the country if it follows sustainable practices.

\section{Concept of the Topic}

'Heritage walks', 'Walking Trails' or 'Heritage trails' refer to guided or unguided tours of the old areas of a city on foot. They may be based on a particular theme or a number of themes related to the historical, social, cultural or political characteristics of the place. It is said that there is no better way to experience and understand a city than to walk in the footsteps of those who once inhabited it. Heritage walks involve taking visitors around the old areas of the city, explaining the history of the places and helping them to learn more about their holiday destination. Heritage walks 
normally concentrate on discovering a place through its 'built heritage' rather than other forms of heritage. It thus contributes to sustainable tourism in a big way. Heritage walks have a great potential in India because of constant international interest in our history, culture and traditions. They have existed for many years now. However, they have only recently been repackaged as 'heritage walks' to appeal to the segment of tourists interested in heritage tourism.

Heritage walks do not always have to be conducted tours. They can be undertaken by an individual himself. The participant is guided by a series of plaques or signs, information contained in brochures and maps or even a recorded explanation about the areas that he/she is passing through. In fact, many people may have already taken part in the heritage walk by themselves and may not be aware about it. People who are interested in exploring cities and their bylanes and who like to observe the differences in characteristics between places while doing so have already taken part in this activity. If they were guided by a map or some other information to enrich their experience of the place, the result would have been even more educational.

\section{Review of Literature}

Rudan (2007) makes a case for walking tours in her paper 'Possibilities for developing cultural tourism in the Municipality of Moscenicka Draga - The case of historical trails'. The objective was to study the current situation of cultural tourism in the Municipality of Moscenicka Draga in Croatia and to explore new ways to promote the same. The region was very popular with sunbathers and adventure seekers but was also a sacred site for the ancient Slavs. The study pointed out that there were five historical trails that were used in ancient times and these could be used again in modern times to boost tourism in the area. It presented a SWOT (Strengths, Weaknesses, Opportunities and Threats) Analysis in order to put forward a case for developing trails in the area. It stressed the need for involvement from tourism boards, local authorities and the local community and also lists out concrete steps that should be taken before the proposal is implemented. It concludes that this type of 'open air museum' will enhance the destination's image and provide it with a competitive edge.

In his paper 'The meanings of a heritage trail in Hong Kong', Cheung (1999) cites the example of the Ping Shan Heritage Trail in Hong Kong. The objective of the paper was to highlight the different interests and interpretations of stakeholders in the heritage trail. It discusses the role of government agencies and the Tang clan who own the structures featured on the trail. It details the campaigns conducted by the Hong Kong Tourist Association which portrayed the city as a mix of traditional 
and modern in order to appeal to international visitors. It puints out that the number of domestic tourists participating in the walk was much higher than foreign tourists even though no special steps were taken to promote the same among this section of visitors. The study attributes this to historical reasons viz. the Hongkongese people's search for their unique identity. Thus, the walks helped to build a sense of belongingness among the domestic visitors. The study concludes by pointing out the changing views of the host community to tourist arrivals, from initial resistance to realization of the economic importance of the same.

In a study on 'Heritage Buildings and Tourism - An Experiential View', Willson et al (2007) explores the experiences of tourists visiting Hawke's Bay, New Zealand. It looks into the specific characteristics of the buildings that influenced the tourists. The study found that the various experiences centered around three themes - visual appeal, personal reflections and engaging experiences. The conclusions drawn are that attention should be paid to the relationship between heritage buildings and tourism. It will consequently help in promoting the destination and in product development in a sustainable manner.

Stone (1994), in 'Presenting the past - A framework for discussion' stresses that heritage resources are important as educational tools. The objectives of the paper were to study how these resources could be interpreted and presented in different ways by archaeologists and indigenous people. One aspect of the study pointed out that there are an increasing number of archaeologists who want the study of the subject to extend beyond classrooms and to the general public. It raises the point that this approach would not necessarily result in an increased protection of the sites. However, it also draws attention to previous studies which say that students who studied the past through an archaeological approach retained more information than those who undertook a document based approach. The study cites findings about the Indian education system, which is significant. The article concludes by listing various measures by which teaching of history can be combined with archaeological study to aid public interpretation.

\section{Heritage Walks around the world}

Many big cities across the globe are encouraging walking tours in a bid to boost tourism. 'London Walks' is one of the foremost companies who conduct these walks. With a history of over 50 years, they can be credited with popularizing this form of touring. With friendly guides and unique story telling they have redefined walking tours. Apart from the most visited sites in London like Westminster Abbey and the British Museum, they cover those associated with dark history too. For example the 'Jack the Ripper Walk' which is guided by a crime historian. Other 
popular walks include the 'Beatles Tours' and 'Charles Dickens' London'. They also conduct walks especially for children which not only includes old historical places but also those associated with popular culture such as the 'Harry Potter Walk'. Thus, they have proved that city tours, and more specifically, heritage walks need not be confined to the traditional view of history. Similar tour companies exist in New York too, where walks take you through the history of the city from its $19^{\text {th }}$ century immigrant neighborhoods, important places in African American history viz. Harlem, other places like Central Park, Ellis Island etc.

While these tours are being conducted by professional architects and historians, Paris has come up with an innovative program to get the local community involved too. The 'Paris Greeter' is a free service offered by local residents to show tourists their favorite places in the city. It offers visitors a unique chance to see the city from the point of view of locals and also to interact with them. This is an excellent example of how the host community can be roped in to promote the tourism of their hometown.

In India, the effort has been taken on mostly by INTACH (Indian National Trust for Art and Cultural Heritage) though it mostly concentrates on the conservation aspect. Other private companies too have now started their own heritage walks. For example, The Bombay Heritage Walks in Mumbai, Bangalore Walks in Bangalore, etc. While The Bombay Heritage Walks is conducted by architects for people interested in the field, Bangalore Walks includes walks for children and corporate alike.

Every city has its own character and walks can tap into that. Law (1991) stresses the need for individuality instead of simply basing new projects on that which has worked elsewhere. Thus, walks can be adapted to suits the needs and wants of the target audience.

\section{Role in Education}

So far, this study has highlighted the tourist potential of heritage walks. However, they can also play a big role in education. Tourism of any kind broadens one's perspective of the world around them. Participating in a heritage walk in order to undertake sightseeing may be one of the objectives for a tourist. However, it will highlight the history and culture of the city and also the need for conservation. The tourist will come away from it feeling enriched. Thus, it will be an educational experience for them.

Walks can also be directly used as an education tool. Younger participants take them up so as to learn about history and culture outside the classroom. It has been 
proven that field trips enrich the subjects that the studenis are learning about. It works as a hands-on approach, enabling students to retain more information from a practical demonstration than a theoretical one. History in particular has always been looked upon as being an uninteresting subject. In this context, field trips such as heritage walks can be especially relevant, serving as a tool to bring history alive in the minds of the students. This study explores the educational contribution of heritage walks. Heritage walks can also be enlightening for local people as pointed out by Cheung (1999) in his paper 'The meanings of a heritage trail in Hong Kong'. He explains how the trail was formulated in order to portray the city as a mix of traditional and modern in order to appeal to international visitors. Instead, it drew more domestic participants who wanted to learn about their city.

\section{Significance of Heritage Walks as a Tool for promoting Sustainable Historical Tourism- the Disclosures from Bangalore}

Heritage walks are a relatively new concept as mentioned before. As of now, they take a very academic and historical approach to city tours which may appeal to only certain sections of the society who have an interest in history. If information about the preferences of potential participants is collected and analyzed it would lead to improvements in the way the walks are conducted. The pilot study conducted at Bangalore tried to determine if the general public prefers the walks being more activity based than information based. As field trips, they could offer students in schools and colleges a different perspective to classroom study of history and bring the subject alive for them. The potential of heritage walks is huge in the country. Bangalore too has heritage walks held by a private company. It makes use of innovative and interactive techniques and targets different sections of the society including children and corporate clients. This study also intended to assess the different ways in which historical resources can be used not only to teach history but also to involve the public in conservation works and generate in them a sense of pride and belongingness. Heritage walks could thus be an important tool to practice sustainable tourism.

\section{Nature and Scope of the Study}

This pilot study on heritage walks takes into account that many travelers who would like to go on holidays that allow them to explore the city they travel to and discover its history. It analyses the potential of walking tours based on feedback from prospective participants in Bangalore city. Though previous studies also include the benefits 
this kind of tourism brings to the local community, this study mainly focus on visitor perceptions and highlighting their needs and wants. It collects information which will be useful for further studies on the same. The sample size of this research is small (75) and confined to one city only. Therefore it is a micro study of the larger issue.

\section{Research Methodology}

A Pilot study was conducted at Bangalore to understand the role of heritage walks as a sustainable tourism tool in the promotion of a destination. The study also aimed to learn the current perceptions of people regarding heritage walks.

A structured questionnaire was used to collect primary data from the respondents. It consisted of questions about the current awareness and beliefs about heritage and heritage walks, their participation in heritage walks in the past and suggestions about how the walks can be made more interesting and appealing to more people. Random sampling was used to collect the data from 75 respondents of the age group of 18-30 years of age. The secondary data sources are books, journals and internet articles.

\section{Findings and Discussion}

The study aimed at exploring the new area of heritage walks in the country. It sought to learn about people's perceptions about heritage walks.

Some of the findings of the study are presented below:

1. It was found that most of the respondents preferred holidays that were based on rest and relaxation. A significant number also said they preferred those that were focused on activities or those that expanded their knowledge about the world and its cultures.

2. Regarding heritage walks, awareness levels of walks conducted in different cities of India were quite high. Most respondents knew about their existence in the country. However, most respondents had never participated in a heritage walk before. It was also found that some had, in fact, undertaken such an activity without the knowledge that it was called a 'heritage walk'. This was either during their own exploration of a destination or through a guided tour. Those who had participated in a walk had done so in known historical places like Hampi, Aihole, London, etc. Although the study was conducted in 
Bangalore, no one had participated in a heritage walk in the city. This is in spite of a walk company existing in Bangalore.

3. The tourist value of heritage walks was also established during the study. Respondents agreed that they could help to boost sustainable tourism and channel tourists into unexplored regions with a rich history. It was also found that walks could help boost tourism among local residents. It could help them to discover their roots and lead to an increase in local pride. Most respondents said that, given the opportunity, they would participate in one in their own hometown.

4. Regarding the preference for the type of tour that would be appealing to them, many respondents said they would be interested in one associated with a legend, mystery or dark history. Interactive sessions were also thought to make the walks more interesting and engaging. It was determined that mostly working people preferred this type of interactive walk.

5. A majority of students and teachers said that they would prefer if a historian or architect accompanied the walk. However, among the older respondents i.e. working people, many were undecided about this. It was found that they would prefer a tour guide or rather be left on their own to explore aided by just a map.

6. By juxtaposing the traditional medium of learning about the history of the place viz. museums against the new concept of heritage walks, the study sought to determine the preference of tourists about the same. It was found that most people said that they would prefer to participate in a walk instead of going to a museum to learn about history. This shows that heritage walks can be promoted as a more interesting way to educate tourists about the history of a place. In India this is especially relevant. In spite of our rich history, our museums are in a decrepit condition and incomparable to the West. Walks can be used to bring history alive in the minds of participants.

7. An overwhelming majority of respondents across categories supported the statement that educational institutions should have activities like fieldtrips of a historical nature to facilitate learning. A good sign was that a majority of teachers strongly supported this. Respondents also thought that such activities would take learning beyond the classroom. It would help students to appreciate history better and retain more information. It was also felt that such an educational experience should not be limited to students alone but should also include older people. This would not only highlight the country's glorious past but also draw attention to the need for conservation of historical places. 
8. Heritage walks could be put to many uses. The study sought to determine if they could be used in the corporate world as an innovative method of team bonding and team building. However, the target group i.e. working people were quite unsure about this. Others like some sections of students surveyed and teachers felt otherwise.

9. The changing nature of the traveler and his/her willingness to experiment was clearly demonstrated in the fact that a large number of respondents said they would take part in a heritage walk at least once to experience something different from their normal routine.

\section{Suggestions}

1. Heritage walks should be marketed as a distinctive part of sustainable historical tourism. Public and private participation is a must for its success. The destination's infrastructure can have a direct impact on the success of a walk. Therefore public authorities should take concrete steps to improve the same. Local residents too should realize the favorable economic and social consequences of a walk and should support them. They can be educated about this aspect so that there is not much resistance to the idea.

2. While promoting sustainable tourism through walks, care should be taken that marketing activities through the right channels reach the target population. Otherwise it can have undesirable consequences. Sites can become too crowded and damage to the structure and ambience can take place.

3. In order for them to work as educational tools, there should be more emphasis on the legends and anecdotes about the place. Explanation about the architecture and other structural details of the built heritage sites should be given only to the niche audience who are interested in those details.

4. Heritage walks should be of different lengths and variety if they are to suit the mind and convenience of different kinds of people and to encourage everyone to participate - the young and the old, ones with lots of energy as well as some who are more constrained and don't interact as much.

5. Heritage walks can be looked at as a type of field trip, thus diversifying the range of such trips in the area of history and differentiating it from a museum visit. It would give children the chance to step out of the classroom and get a 'hands on approach' to the study of history. 


\section{Conclusion}

Historical resources can play a big role in promoting the tourism of a destination in a sustainable manner. However, their role in education is often overlooked. History is normally considered to be a boring subject. By using an innovative concept like heritage walks, it can be made fun and can be a learning experience for participants. For students, this is especially important as it will not only encourage the study of history but also highlight the urgent need for conservation of our built heritage structures. From the findings of the study conducted we can conclude that heritage walks are a new area of tourism with great potential. This is not only because of our wealth of resources but also because of the novelty of the concept and its uniqueness as a sustainable tourism product.

\section{References}

Rudan, E. (2007). 'Possibilities for developing cultural tourism in the Municipality of Moscenicka Draga - the case of historical trails'. Tourism \& Hospitality Management. June 2007. Vol. 13 (Issue 2), p515-522

Cheung, S. (1999), 'The meanings of a heritage trail in Hong Kong', Annals of Tourism Research. Volume 26 (Issue 3). July 1999, Pages 570-588 Nuryanti, W. (1996). 'Heritage and Postmodern Tourism'. Annals of Tourism Research, Vol. 23, No. 2, pp. 249-260

DeWitt, J., Storksdieck, M. (2008). A Short Review of School Field Trips: Key Findings from the Past and Implications for the Future. Visitor Studies, Volume 11(Issue 2), pages 181 - 197

Economic Times -

http://economictimes.indiatimes.com/News/News_By_Industry/Services/ Budget_disappoints_travel_industry_except_for_heritage_tourism/articleshow $/ 2828327$.cms

Markwell, K., Stevenson, D., Rowe, D. (2004), 'Footsteps and memories: interpreting an Australian urban landscape through thematic walking tours'. International Journal of Heritage Studies. Volume 10 (Issue 5), pp 457- 473

Mason, R. (2005), 'Museums, galleries and heritage - Sites of meaning-making and communication'. Heritage, Museums and Galleries - An Introductory Reader, pp 200-214. Oxon. Routledge

Stone, P. (2005). 'Presenting the past - A framework for discussion', Heritage, Museums and Galleries - An Introductory Reader. pp 215-227. Oxon. Routledge

Willson, G, Mclntosh, A. (2007). Journal of Heritage Tourism. Dec2007. Vol. 2 (Issue 2), p75-93

Nuryanti, W. (1996). 'Heritage and Postmodern Tourism'. Annals of Tourism Research, Vol. 23, No. 2 , pp. $249-260$

http://whc.unesco.org/en/about/

http://whc.unesco.org/en/164/ 
http://www.planninginstitute.org/index.php? option = content\&task=view\&id $=142 \&$ ltemid

Cyprus walks the walk. Travel Weekly: The choice of Travel Professionals. 06/30/2006. Issue 1827

Murphy, C., Boyle, E., (2006), Testing a conceptual model of cultural tourism developemtn in the post - industrial city: A case study of Glasgow. Tourism and Hospitality Research - The Surrey Quarterly Review, Volume 6 (Issue 2), pages 111-128

Gupta, S. (2004). Glimpses of Pune's Heritage - A Mosaic. Pune: INTACH.

DeWitt, J., Storksdieck, M. (2008). A Short Review of School Field Trips: Key Findings from the Past and Implications for the Future. Visitor Studies, Volume 11 (Issue 2), pages $181-197$

http://www.heritage-trails.cz/fx/en/tourlist/tt-hiking_walking/tourlist.html

http://www.walks.com/Homepage/default.aspx

hHtp://www.walks.com/Homepage/Jack_the_Ripper/default.aspx

http://www.nyctours.com/pubtours.html

hHtp://www.parisiendunjour.com/

http://www.india-seminar.com/2003/530/530\%20debashish\%20nayak.htm

http://www.intach.org/living_heritagefestivals.htm

http://popularsikh.com/node/76206

http://www.bangalorewalks.com/exploriences.htm 